\title{
THERMODYNAMIC INVESTIGATIONS OF BIOLOGICAL MACROMOLECULES
}

\author{
P. L. PRivalov \\ Institute of Protein Research, Academy of Sciences of the USSR, Poustchino, Moscow Region, USSR
}

\begin{abstract}
The lecture is devoted to a consideration of the main possibilities, concepts and perspectives of a thermodynamic approach to the study of structures and conformational mobilities of biological macromolecules in solution. An analysis of data obtained by scanning and reactive calorimetry methods, as well as from the kinetics of hydrogen exchange is given for some types of biological macromolecules. The relation of thermodynamical functions determining the stability of the molecule and the mobility of its local regions with the structure and biological function is discussed.
\end{abstract}

In thinking over the content of my plenary lecture from the sphere of biology at this conference on thermodynamics I confess that I had great difficulties.

On the one hand, thermodynamic problems are undoubtedly central in studying the living state, since life is in a way nothing else than the process of transformation of substance and energy.

On the other hand, a thermodynamic approach to biological systems induces great scepticism, not only amongst specialists of thermodynamics but of biology as well. This scepticism is in general justified since the thermodynamic approach has been developed on simple systems, and it is by no means evident that this approach is able to give anything more than trivial conclusions and speculations for complicated systems.

However, during the recent decades there was a great shift both in biology and in thermodynamics. Biologists have learned not only to divide complex biological systems into simpler constituents down to separate biological molecules, but also have realized that the clue to the understanding of biological phenomena does lie at the molecular level, that is, the level which is really described by physical terms and studied by physical methods.

As for thermodynamics, the main progress achieved here is the development of micromethods in calorimetry. This is significant since the application of experimental methods of thermodynamics to objects of molecular biology was restricted by the accessible amount of highly purified biological compounds. But since these practical difficulties were overcome and we know now how to measure microcalories in micrograms of limited material (for microcalorimetry see reviews ${ }^{1-5}$ ), we are faced directly with the same principal question, though on another level-the question of applicability of thermodynamics to biological systems on this level and usefulness of obtained information for biology. This question is by no means as simple as it may seem, since even the molecular level of biology qualitatively differs from that with which chemical thermodynamics deals normally. This difference is connected in the first place with the following three properties of biological molecules:

(1) Colossal dimensions. Their molecular weight is within the limits of $10^{4}-10^{8}$ daltons. Thus, individual molecules in some respect can be regarded as macroscopic systems and are called 'macromolecules'.

(2) Exclusive orderliness. In biomacromolecules the relative position of each atom is strictly fixed in space.
But in contrast to crystals, the position of each atom is defined individually, forming a unique structure or conformation. Therefore according to Schrödinger they are often called aperiodic crystals. ${ }^{6}$

(3) The capability to be in different states or conformations depending on conditions. Transitions between conformations are not connected with the disruption or redistribution of covalent bonds in a macromolecule.

According to modern concepts, the biological function of many molecules is closely connected with their conformational transitions and they perform these transitions during functioning in the biosystem.

However, transitions can be induced artificially by changing the environment or conditions for the macromolecule. If these changes are extremal, an extreme transition will take place-a transition into a completely random state. Instead of a strictly defined threedimensional structure we will obtain a polymer chain folded into a structureless random coil. This state is called a denatured one in contrast to the initial native state.

In reality the situation is quite the contrary; the initial state is the denatured and not the native one, since the biological macromolecule is synthesized as a linear polymer which then folds into the native conformation. In the process of formation of the macromolecular threedimensional structure the information contained in the chemical structure of its polymer chain (the so-called primary structure) is realized. Thus, this transition from the random state into the ordered one is performed at the expense of internal moving forces. Therefore the study of this transition is principally important for the understanding of the process of self-organization of the threedimensional structure of biological macromolecules, for the understanding of the forces determining and maintaining this structure.

From the fact that in the living system the transition from the structureless state $(D)$ into the native state $(N)$ takes place, we can suggest that this transition should be reversible. The conditions of reversibility were found in vitro only in a very limited number of cases. Nevertheless, we are inclined to think that the observed irreversibility is caused by different secondary phenomena (such as aggregation), but the transition itself is in principle reversible. ${ }^{7}$ In any case, I will speak only about the results obtained by studying completely reversible processes.

Denaturation can be induced by quite different sharp changes to the protein: by high temperature, pressure, high acid or alkali concentration, or by such 
compounds as guanidine hydrochloride or urea which are even called denaturants. (For a review on denaturation see Ref. 8.)

As the three-dimensional structure at denaturation breaks down and the macromolecule loses its specific properties, we can trace this process by using any parameter sensitive to the state. From the thermodynamic point of view, the most interesting is the energy parameter-the enthalpy of the process, which can be directly measured calorimetrically. It has a most fundamental physical meaning and is directly connected with the number and strength of the bonds disrupted during the structural transition.

Let us begin the consideration of the denaturation process with denaturation of globular proteins which are compact molecules with a comparatively low molecular weight. As an example we shall take a typical globular protein-lysozyme. As is seen from Fig. 1, it is really compact and extremely ordered in the native state. If the aqueous solution of lysozyme is heated, the protein will sooner or later denature; the internal bonds maintaining it will disrupt and it unfolds, absorbing the 'denaturation heat'. The thermal picture of this process obtained on the scanning microcalorimeter is given in Fig. 2. We see the

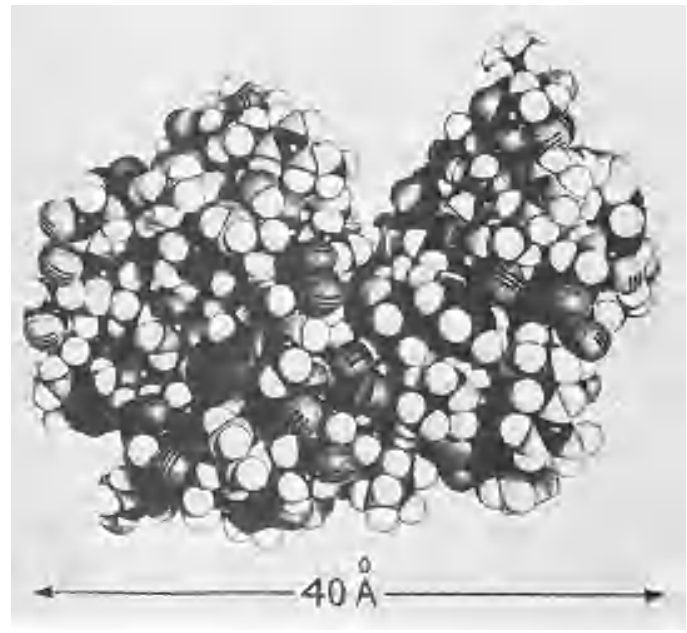

Fig. 1. Atomic model of lysozyme according to Phillips.

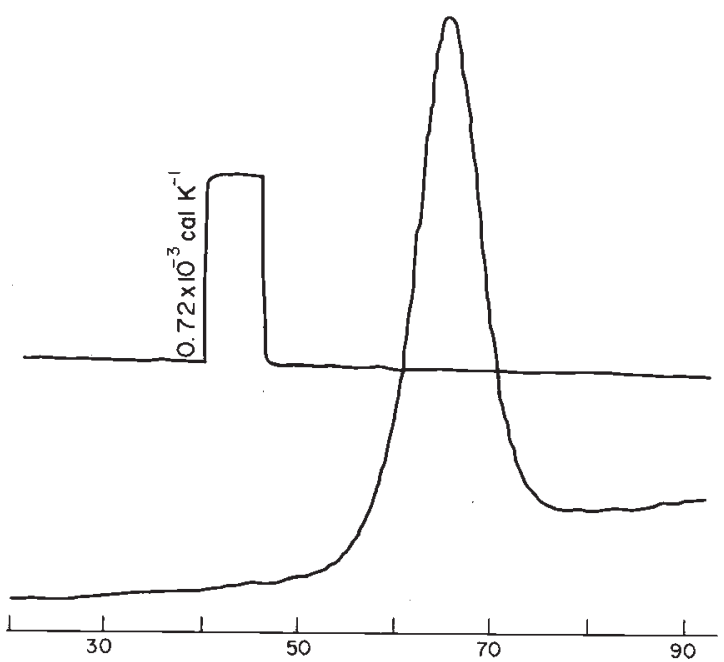

Fig. 2. Heat absorbance in the heated lysozyme solution ( $\mathrm{pH} 2.5$, concentration $0.18 \%$, protein content $2.3 \mathrm{mg}$ ) recorded by the scanning microcalorimeter.

heat capacity change of dilute lysozyme solution with temperature.

Attention is attracted to the fact that an intensive heat absorbance, connected with denaturation, proceeds in a comparatively narrow temperature interval. But before and after denaturation only an insignificant linear increase of thermal capacity of the system is observed. It should be also noted that during denaturation the protein heat capacity increases by a discrete value of $\Delta C_{p}{ }^{d}$.

The given picture is typical for globular proteins. This is evidenced by Fig. 3 which gives the lysozyme partial heat capacity in aqueous solutions at different $\mathrm{pH}$, and by Fig. 4 which gives the temperature dependence of partial heat capacity in different globular proteins. ${ }^{10}$

Now let us consider denaturation by acid on the same example of lysozyme.

If the protein is titrated by an acid and the heat effect of titration is measured with a reaction isothermal microcalorimeter, the enthalpy change of the protein (calculated per mole) will be the one presented in Fig. 5. This example is taken from, ${ }^{11}$ but analogous pictures were also observed by other authors for other proteins (see, for

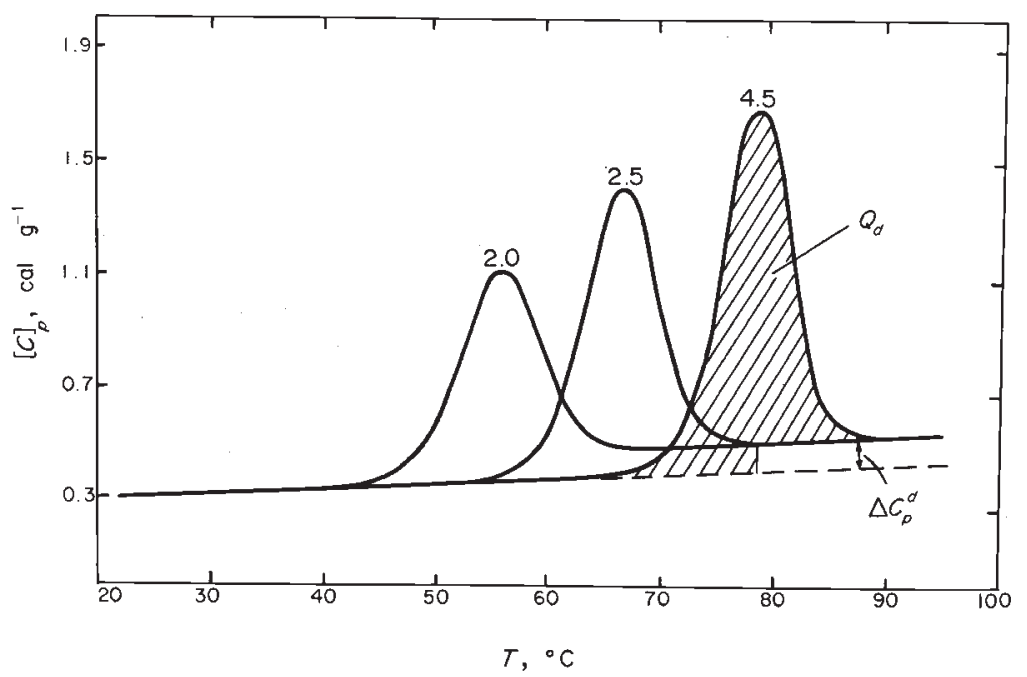

Fig. 3. Temperature dependence of the partial heat capacity of lysozyme in solutions with different $\mathrm{pH}$ values. 


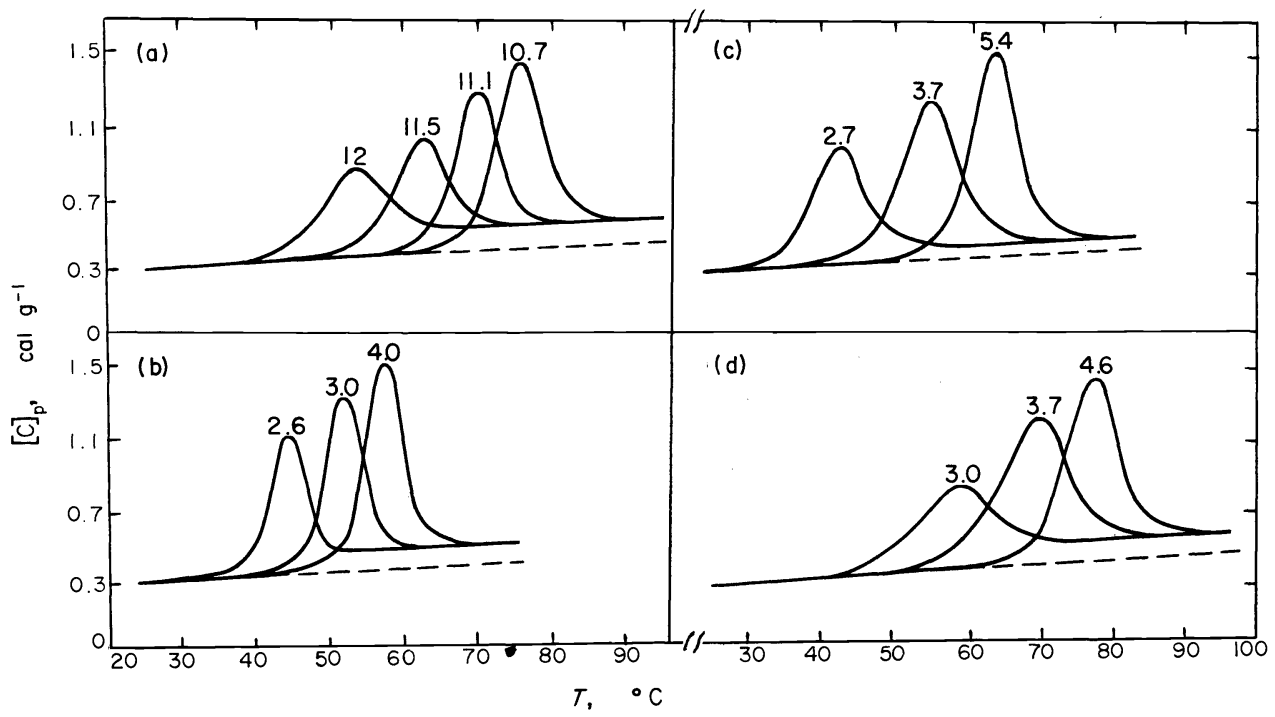

Fig. 4. Temperature dependence of the partial heat capacity of different globular proteins at different $\mathrm{pH}$. (a) Myoglobin, (b) $\alpha$-chymotrypsin, (c) ribonuclease, (d) cytochrome C.

example ${ }^{12,13}$ ). As is seen from Fig. 5, at first the enthalpy changes very little with decrease in $\mathrm{pH}$ (this region is given in detail in Fig. 9), but then the enthalpy abruptly increases in a comparatively narrow $\mathrm{pH}$ region, where the protein denatures. It is also seen that the enthalpy of denaturation and the region of $\mathrm{pH}$ in which denaturation proceeds, directly depend on the temperature of protein titration.

And finally, the third example of denaturation by a denaturant, e.g. guanidine hydrochloride $(\mathrm{GuHCl})$, is given in Fig. 6. The enthalpy change on protein titration by $\mathrm{GuHCl}$ was also determined on the isothermal microcalorimeter. The given figure was taken from Ref. 14, but analogous data were obtained by other authors as well (see, for example ${ }^{15}$ ). As is seen, the heat effect here is somewhat more complicated: a significant change of enthalpy takes place from the very start of protein titration

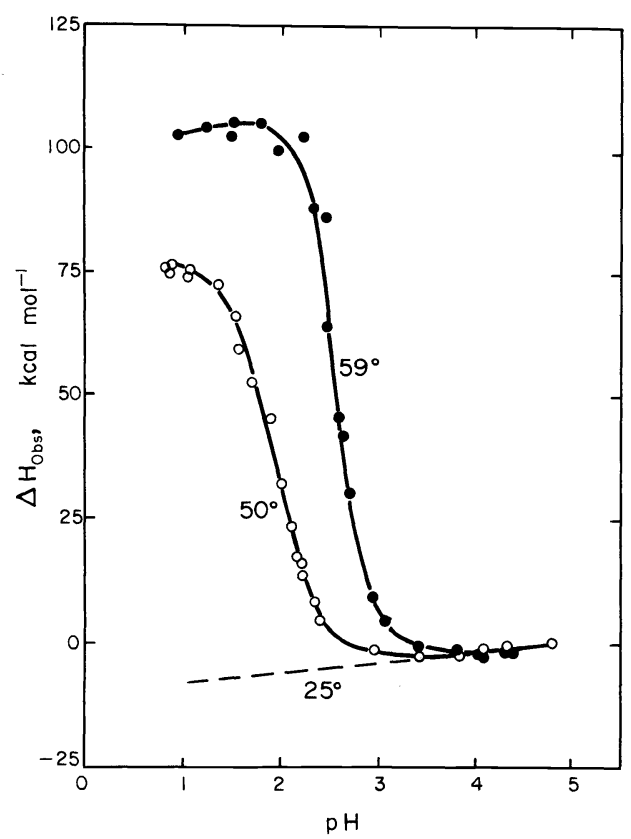

Fig. 5. Enthalpy change of lysozyme at its titration by acid at different temperatures.

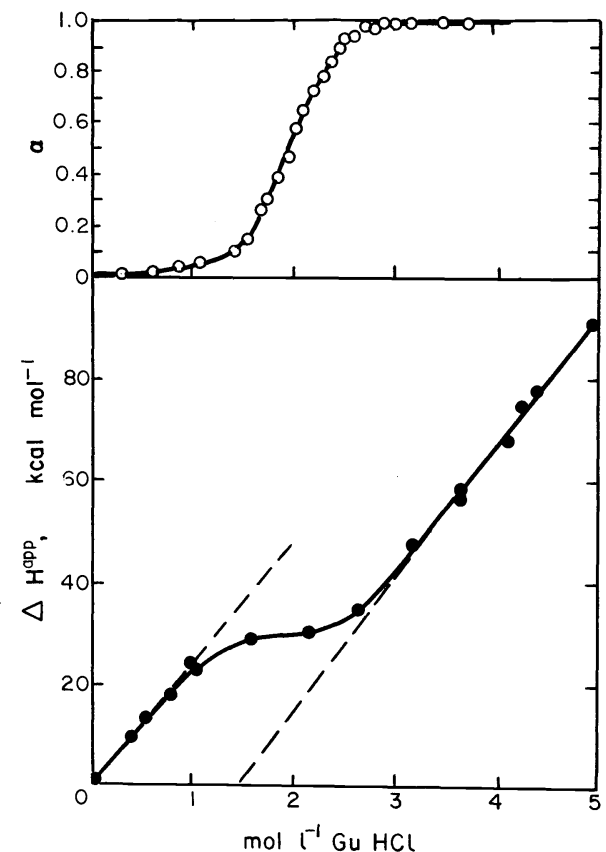

Fig. 6. Enthalpy and optical activity change of lysozyme at its titration by $\mathrm{GuHCl}$ at $25^{\circ} \mathrm{C}$ and $\mathrm{pH} 1.5$.

by $\mathrm{GuHCl}$. But a comparison of this picture with the picture of changes in other parameters characterizing the protein (for example, the optical parameters given in Fig. 6a) shows that this is the heat of solvation of the native protein in $\mathrm{GuHCl}$, which is seen to be negative. The denaturation absorbance of heat proceeds at higher concentrations of $\mathrm{GuHCl}$, then the solvation effect is observed again, but this time it is the denatured protein that is solvated.

The region of denaturation and the denaturation enthalpy here, as in the case of acid titration, depend on temperature (Fig. 7). However, it is more difficult to determine the enthalpy of denaturation by guanidine hydrochloride than the enthalpy of denaturation by an 


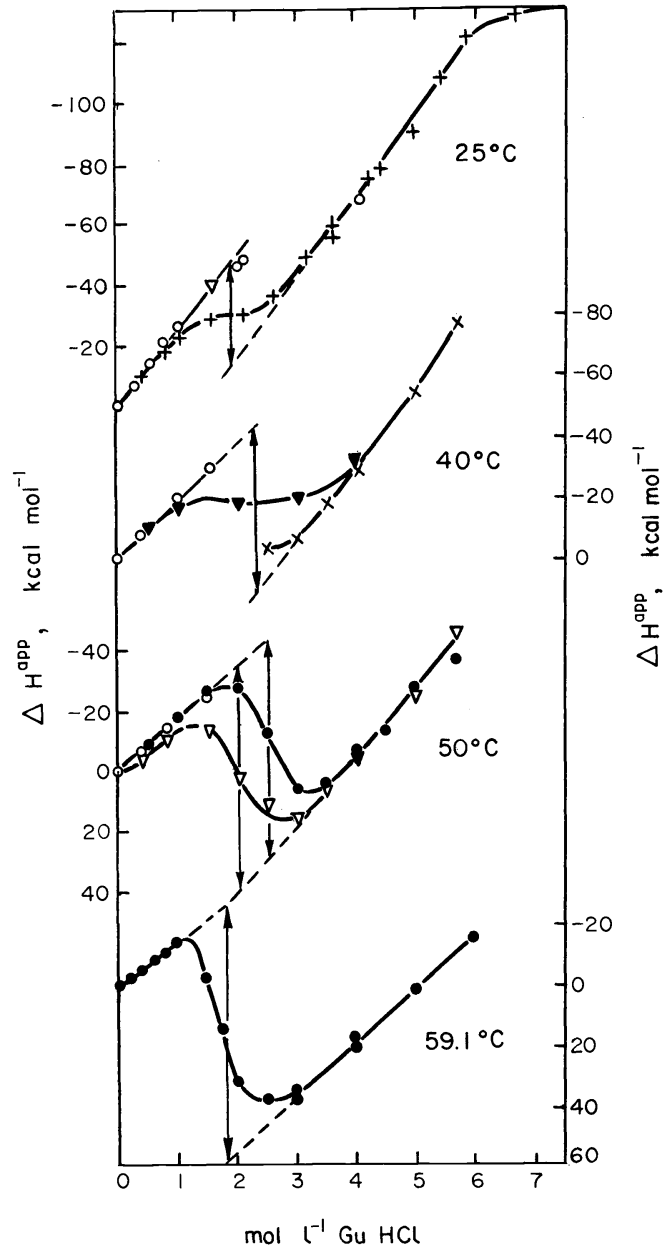

Fig. 7. Enthalpy change of lysozyme at its titration by $\mathrm{GuHCl}$ at different temperatures and $\mathrm{pH}$. $+-\mathrm{pH} 1.3 ; \times-\mathrm{pH} 2.1 ; \nabla-\mathrm{pH}$ $2.5 ; \nabla-\mathrm{pH} 3.0 ; \mathrm{O}-\mathrm{pH} 3.5 ; \mathrm{O}-\mathrm{pH} 4.5$.

acid, since the solvation effects are significantly greater than the ionization ones. Nevertheless, if the solvation effects as well as the ionization ones are correctly taken into account $\left(\right.$ see $\left.^{11,14}\right)$, it appears that the denaturation enthalpies determined for quite different denaturation processes agree (see Fig. 8). We obtain a certain common function depending only on the temperature and not on $\mathrm{pH}$ and the guanidine content. The slope of the $\mathrm{d} \Delta H^{\mathrm{d}} / \mathrm{d} T$ function will precisely correspond to the heat capacity increase $\Delta C_{p}{ }^{d}$ as it must if the Kirchhoff law is valid here $\left[\left(\mathrm{d} \Delta H^{d} / \mathrm{d} T\right)=\Delta C_{p}{ }^{d}\right]$.

This fact was quite unexpected. Indeed, it was much simpler to assume that different denaturing agents bring the protein into different states with a different residual structure. ${ }^{16}$ In fact it appeared that these states do not differ in enthalpy. Hence the result was that from the thermodynamic point of view the denatured state of protein is a certain unique macroscopic state qualitatively differing from the native.

However, it must be shown that it is really a quite definite macroscopic state. In other words, that it is entirely defined by thermodynamical functions.

We will describe the protein state in coordinates of $T$ and $\mathrm{pH}$ taking the values of $T^{\circ}=25^{\circ} \mathrm{C}$ and $\mathrm{pH}^{\circ}=7.0$ as standard.

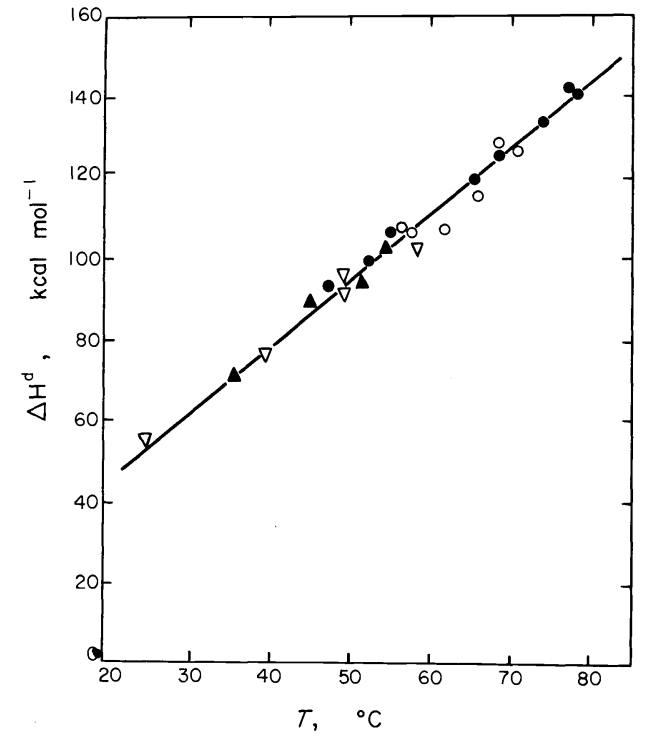

Fig. 8. Lysozyme denaturation enthalpy obtained by different methods under various conditions as a function of denaturation temperature. Without GuHCl: - - scanning calorimetry ( $T$ variable, $\mathrm{pH}$ constant); $\mathrm{O}$-isothermal calorimetry ( $\mathrm{pH}$ variable, $T$ constant). In the presence of GuHCl: $\Delta$-scanning calorimetry ( $T$ variable, $\mathrm{GuHCl}$ constant), $\nabla$-isothermal calorimetry (GuHCl variable, $T$ constant).

Then for the enthalpy and entropy of the native state we have

$$
\begin{aligned}
H^{N}(T, \mathrm{pH}) & =\int_{T^{0}}^{T}\left(\frac{\partial H}{\partial T}\right) \frac{\mathrm{d} T}{\mathrm{pH}}+\int_{\mathrm{pH}^{0}}^{\mathrm{pH}}\left(\frac{\partial H}{\partial \mathrm{pH}}\right)_{T} \mathrm{dpH} \\
& =\int_{T^{0}}^{T}\left[C_{p}\right]_{\mathrm{pH}}^{N} \mathrm{~d} T+H^{N}(\mathrm{pH}), \\
S^{N}(T, \mathrm{pH}) & =\int_{T^{0}}^{T}\left(\frac{\partial S}{\partial T}\right)_{\mathrm{pH}} \mathrm{d} T+\int_{\mathrm{pH}}^{\mathrm{pH}}\left(\frac{\partial S}{\partial \mathrm{pH}}\right)_{T} \mathrm{dpH} \\
& =\int_{T^{0}}^{T} \frac{[C]_{\mathrm{pH}}^{N}}{T} \mathrm{~d} T+S^{N}(\mathrm{pH}) .
\end{aligned}
$$

And for the denatured state we have:

$$
\begin{aligned}
H^{D}(T, \mathrm{pH})= & \int_{T^{0}}^{T_{d}}\left[C_{p}\right]_{\mathrm{pH}}^{N} \mathrm{~d} T+\left[\Delta H_{d}\right]_{T_{d}}+\int_{T_{d}}^{T}\left[C_{p}\right]_{\mathrm{pH}}^{D} \mathrm{~d} T \\
& +H^{N}(\mathrm{pH}) \\
= & {\left[\Delta H_{d}\right]_{T_{d}}-\int_{T}^{T_{d}}\left(\Delta\left[C_{p}\right]_{d}\right)_{\mathrm{pH}} \mathrm{d} T+H^{N}(\mathrm{pH}), }
\end{aligned}
$$

$S^{D}(T, \mathrm{pH})=\frac{\left[\Delta H_{d}\right]_{T d}}{T_{d}}-\int_{T}^{T_{d}}\left(\Delta\left[C_{p}\right]_{d}\right)_{\mathrm{pH}} \mathrm{d} \ln T+S^{N}(\mathrm{pH})$.

As for the Gibbs functions, they can be determined in the cases of native and denatured protein from a combination of the enthalpy and entropy:

$$
\begin{aligned}
G^{N}(T, \mathrm{pH}) & =H^{N}(T, \mathrm{pH})-T . S^{N}(T, \mathrm{pH}), \\
G^{D}(T, \mathrm{pH}) & =H^{D}(T, \mathrm{pH})-T . S^{D}(T, \mathrm{pH}) .
\end{aligned}
$$


Here all the functions depending on temperature are determinable from the scanning calorimetry, data from which we can find the $\Delta H_{d},\left[C_{p}\right]$ and $\Delta\left[C_{p}\right]_{d}$ values.

To determine the functions depending on $\mathrm{pH}$, the data of isothermal measurements on native protein are required, i.e. the potentiometric and calorimetric titration curves (see Fig. 9). We determine from them the enthalpy and the Gibbs energy of ionization of the native protein having in mind that

$$
G^{N}(\nu)=-2.303 \cdot R T \int_{\gamma_{0}}^{\gamma} \mathrm{pH}(\nu) \mathrm{d} \nu
$$

where $\gamma$ is the number of protons bound to the protein. Hence we can determine the entropy of ionization

$$
S^{N}(\mathrm{pH})=\frac{H^{N}(\mathrm{pH})-G^{N}(\mathrm{pH})}{T_{0}}
$$

Thus, using scanning calorimetry, isothermal calorimetry and potentiometric titration data we can, in principle, obtain thermodynamic functions describing the state of the native and denatured protein over a wide range of $\mathrm{pH}$ and temperature (for details see Ref. 11).

However, let us show that these functions are thermodynamic parameters of the protein.

For this it is necessary to demonstrate that by moving to one and the same point of the phase space in different ways we obtain the same value for the protein thermodynamic functions. Such an investigation was made in our laboratory by Pfeil ${ }^{11,17}$ who studied different cyclic processes of the type given in Fig. 10. As a result, it was shown that the functions determined in this way are independent of the mode of reaching the point determined by the $\mathrm{pH}$ and $T$ coordinates. Thus, the state of the protein is really determined thermodynamically and the protein has two such states: the native and the denatured one.

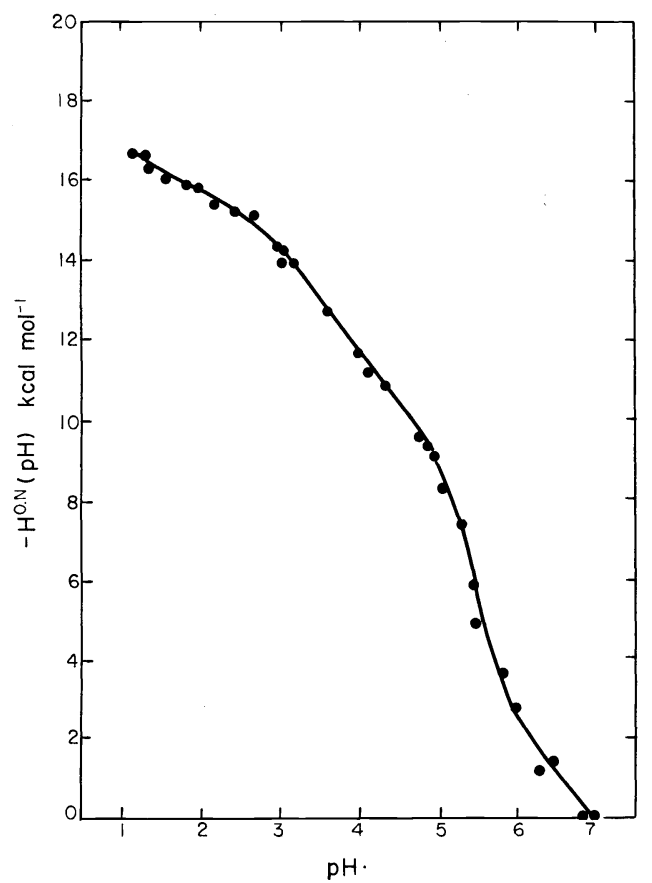

Fig. 9. Microcalorimetric titration curve of native lysozyme at $25^{\circ} \mathrm{C}$.
Thermodynamic functions describing the state of lysozyme are given in Figs. 11-14.

As is seen from Fig. 11, the enthalpy difference between the native and denatured states of the protein does not

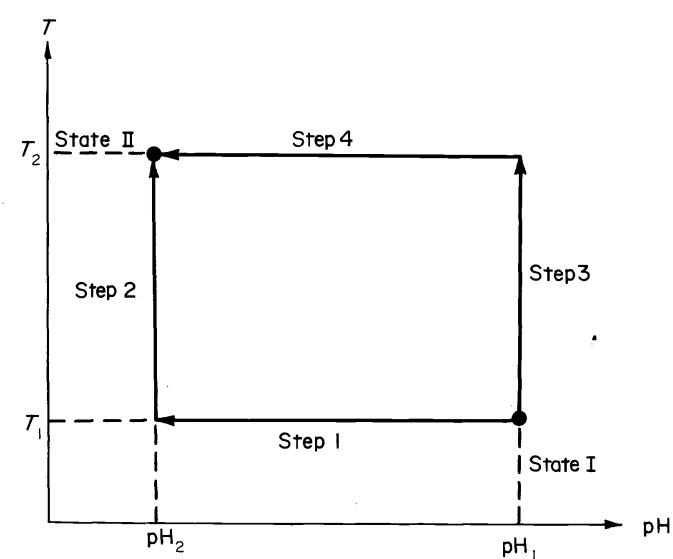

Fig. 10. The transition from state I to state II by two different ways.

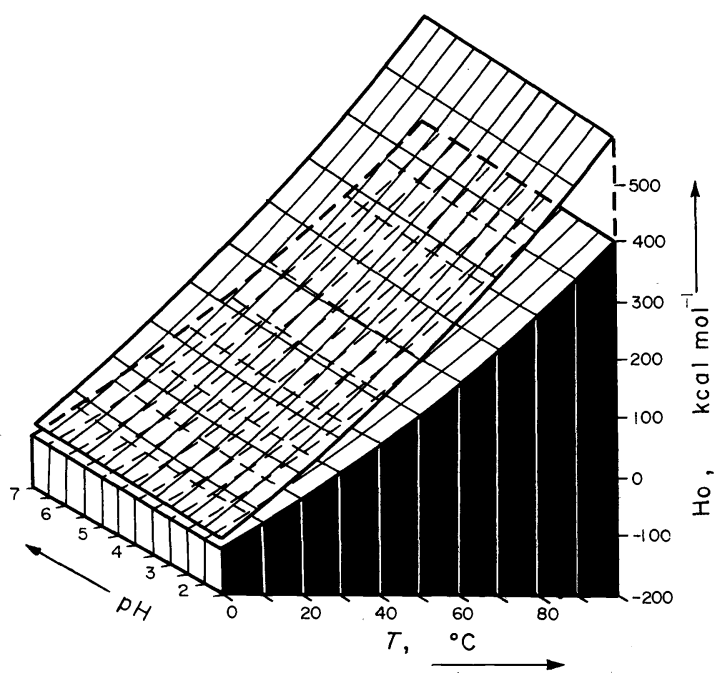

Fig. 11. Enthalpy of native and denatured lysozyme as a function of $\mathrm{pH}$ and $T$.

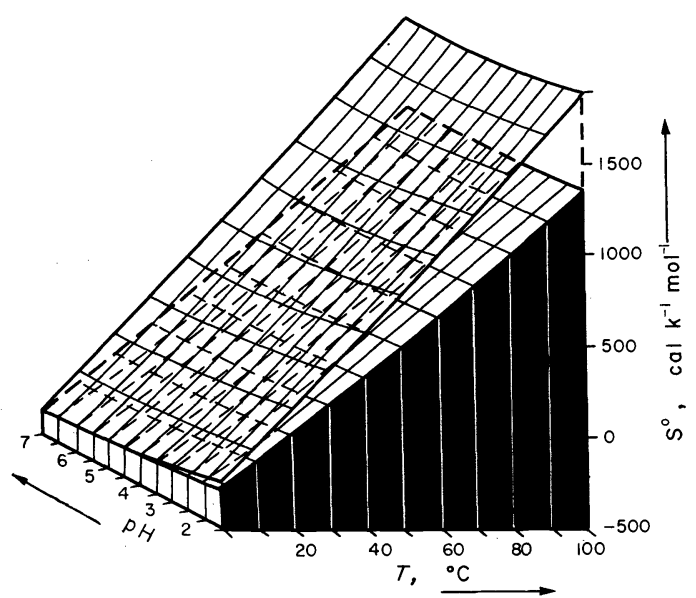

Fig. 12. Entropy of native and denatured lysozyme as a function of $\mathrm{pH}$ and $T$. 


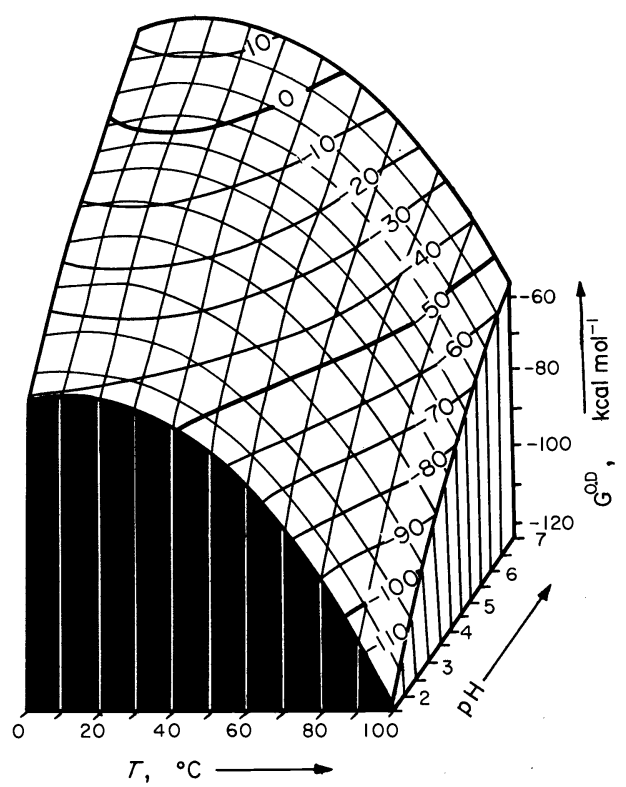

Fig. 13. Gibbs energy of native lysozyme as a function of $\mathrm{pH}$ and $T$.

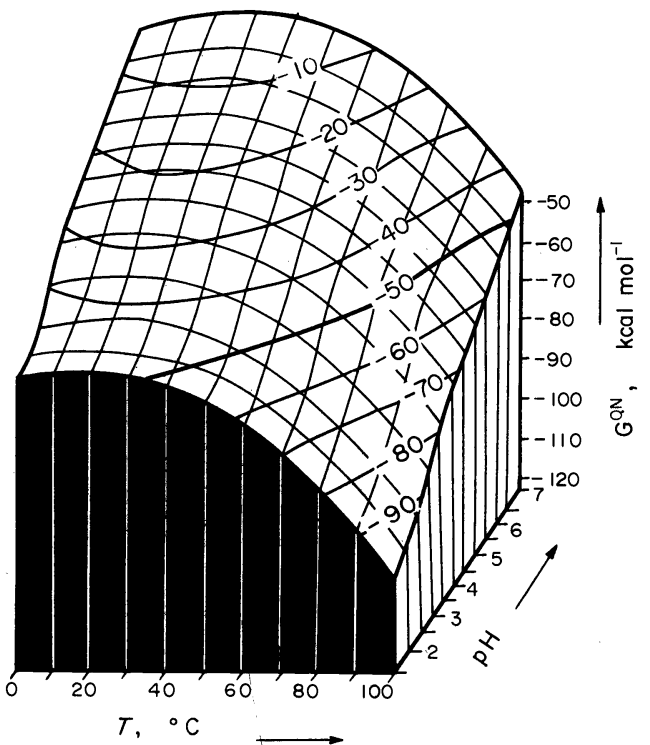

Fig. 14. Gibbs energy of denatured lysozyme as a function of $\mathrm{pH}$ and $T$.

depend on $\mathrm{pH}$ but depends on the temperature. This difference varies for different proteins (Fig. 15). It has been shown ${ }^{10}$ that the steeper the slope of these functions, the greater is the number of contacts between non-polar groups in the protein. The value of enthalpies at the point of intersection of these reactions $\left(\sim 100^{\circ} \mathrm{C}\right)$ is determined by the saturation of the structure with hydrogen bonds. Thus, we have directly arrived at the question of bonds stabilizing the protein native structure and the principles determining it.

From this point of view, the most interesting is the difference between the Gibbs functions $\Delta G$ of the denatured and native protein. For lysozyme it is given in Fig. $16 .{ }^{17}$ Figure 17 presents the cross-sections of these functions for the five different proteins at the $\mathrm{pH}$ value corresponding to their maximal stability. ${ }^{10}$

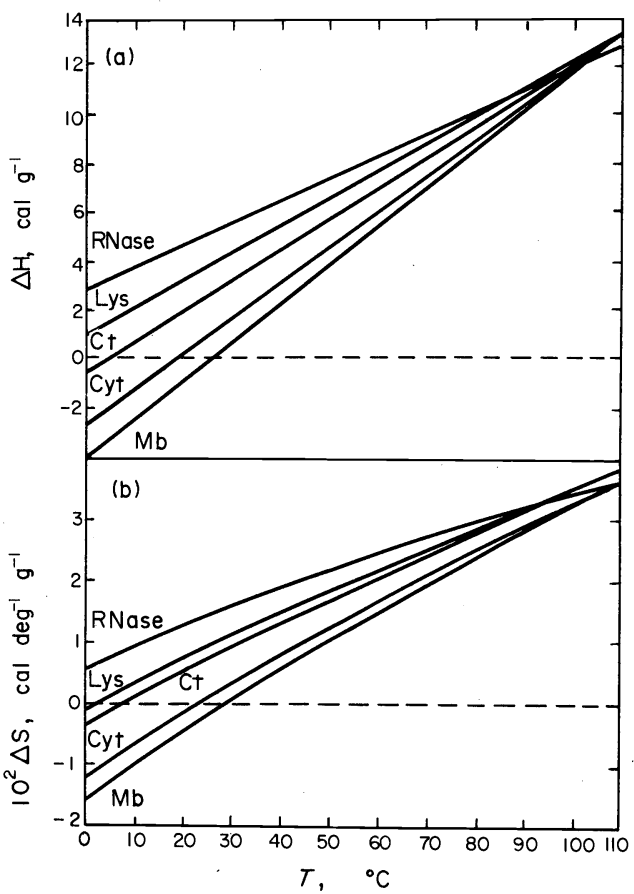

Fig. 15. The enthalpy and entropy differences of denatured and native proteins: ribonuclease (RNase), lysozyme (Lys), chymotrypsin (ct), cytochrome C (Cyt) and myoglobin (Mb).

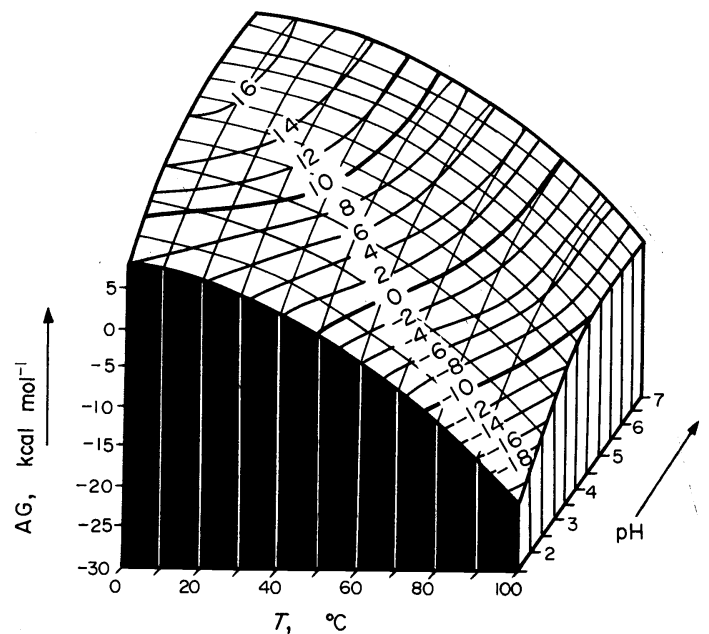

Fig. 16. The difference of Gibbs energy of denatured and native lysozyme in the $\mathrm{pH}$ and $T$ coordinates.

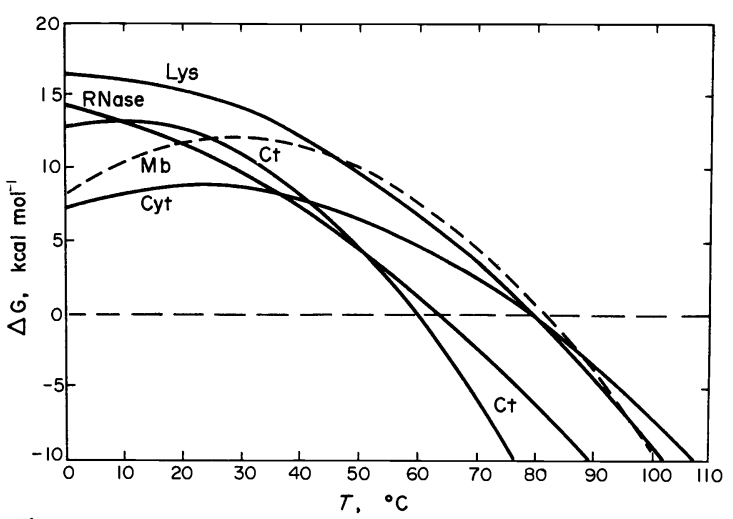

Fig. 17. Temperature dependence of Gibbs energy difference of denatured and native proteins (ribonuclease, lysozyme, chymotrypsin, cytochrome and myoglobin). 
Three points attract our attention.

The first is that these functions for the five quite different proteins are very alike.

The second is that these functions reach their maximal values in the region of physiological temperatures.

And finally, the magnitude per se of the stabilization energy of the native structure of this very large molecule is not great at all, being $10-15 \mathrm{kcal} / \mathrm{mol}$. It can be considered to be significant only in the case when the whole macromolecule is regarded as something indivisible, an entity. Can this be really so?

Up till now we have only assumed that the protein abruptly passes from the native into the denatured state and back. However, the question whether denaturation can be considered as a transition between two states and whether the protein has intermediate states has been for a long time hotly discussed in the literature. The solution of this problem is apparently one of the most significant achievements in thermodynamics of biopolymers. ${ }^{10,18-21}$

Let us assume that the protein really has only two thermodynamically stable states and that the transition proceeds between them. In this case the temperature dependence of the transition can be described by the Van't Hoff equation expressing the equilibrium constant through any parameter $\vartheta$ sensitive to the state

$$
R \frac{\mathrm{d} \ln \frac{\vartheta}{1-\vartheta}}{\mathrm{d} \frac{1}{T}}=\Delta H^{\mathrm{eff}} .
$$

Hence for the effective or Van't Hoff enthalpy of the process we have

$$
\Delta H^{\mathrm{eff}}=\frac{R T^{2}}{\vartheta(1-\vartheta)} \frac{\mathrm{d} \vartheta}{\mathrm{d} T}
$$

For the midpoint of the transition where $\vartheta=\frac{1}{2}$ we obtain

$$
\Delta H_{d}^{\mathrm{eff}}=4 R T^{2} \frac{\mathrm{d} \vartheta}{\mathrm{d} T} .
$$

However, for the calorimetric curve the parameter which determines the degree of the reaction progress $\vartheta$ is the portion of the heat absorbed for the given temperature $\vartheta=\left[Q(T) / Q_{d}\right]$. Therefore

$$
\Delta H_{d}^{\text {eff }}=\frac{4 R T^{2}}{Q_{d}}\left(\frac{\mathrm{d} Q}{\mathrm{~d} T}\right)_{1 / 2}=\frac{4 R T^{2}\left(\Delta C_{p}\right) \max }{Q_{d}} .
$$

Here $\left(\Delta C_{p}\right)^{\max }$ is the height of the heat absorbance peak at the midpoint of the transition.

For the real molar enthalpy we have, according to the definition

$$
\Delta H_{d}^{\mathrm{cal}}=M Q_{d}
$$

If the assumption that denaturation is a transition between only two states is a valid one, the effective enthalpies should be equal to the real ones. In other words, the ratio

$$
\frac{\Delta H_{d}^{\text {cal }}}{\Delta H_{d}{ }^{\text {eff }}}=\frac{M Q_{d}^{2}}{4 R T^{2}\left(\Delta C_{p}\right)^{\max }}
$$

should be close to unity.

A detailed investigation showed ${ }^{10}$ that in small compact globular proteins it is really close to unity (see Fig. 18). The deviation does not exceed $4 \%$.

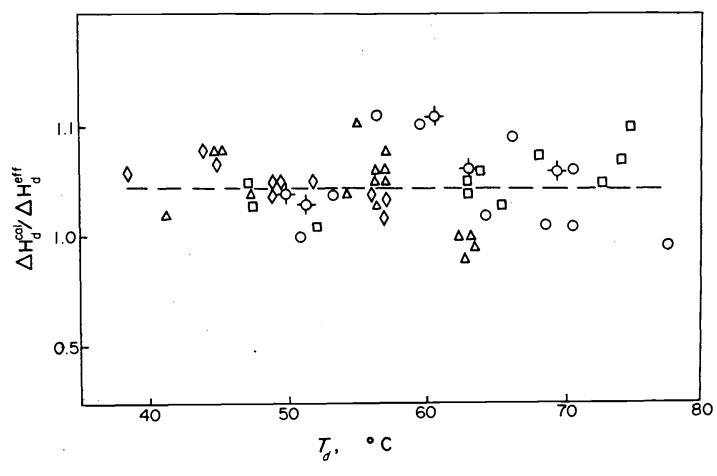

Fig. 18. The ratio of calorimetric and effective denaturation enthalpy of the five globular proteins under different conditions. $O-$ myoglobin, $\Delta$-ribonuclease, $O-$ cytochrome $\mathrm{C}, \diamond-\alpha$ chymotrypsin, $\mathrm{O}-$ lysozyme.

Thus, we arrive at the conclusion that denaturation of globular proteins is a highly cooperative process. The protein really performs a transition from one state into the other as an entity, without intermediate thermodynamically stable states.

It is not easy to understand how this proceeds in such a complex and extensive system as protein. It is still more difficult to understand this if we take into account that according to the latest kinetic data this transition of proteins into the structure-free state as well as the reverse transition into the native state is very fast and occurs in a millisecond time interval. ${ }^{22,23}$ How is this accomplished in a system with a colossal number of degrees of freedom in the unfolded state? If the protein polypeptide chain during transition had to pass through all possible states, then years would be required to form the native structure according to very modest calculations. ${ }^{24}$ Hence we have to conclude that the polypeptide chain does not search for all the possible variations of packing, but folds in a definite sequence and in a definite way. In other words, in multidimensional phase space the protein moves along a definite trajectory towards the region corresponding to the native state.

Here we have come to the most mysterious question of protein physics, which is probably the most crucial and principally important. The difficulty of solving this problem is aggravated by the fact that a property of such exclusive cooperativity is the privilege of globular proteins which are highly refined complicated systems and this property cannot be modelled by simplified models-synthetic polymers.

Now I will pass to another biological entity in which this property is not displayed in spite of the fact that this object is a formation of the same compactness as globular proteins with approximately similar dimensions. It belongs to another class of biological compounds-nucleic acids. I have in mind transfer RNA.

As is seen from Fig. 19, the tRNA is as compact as the globular protein. ${ }^{25,26}$ Its molecular weight is 25,000 daltons, which is close to that of chymotrypsin, a typical globular protein.

Nevertheless, the tRNA melting curve (see Fig. 20) differs radically from what we have for globular proteins. ${ }^{27}$ (The figure presents the curve of melting of valine-specific tRNA. But its three-dimensional structure apparently does not differ from the three-dimensional structure of phenylalanyl-tRNA determined by the groups of Rich and Klug and given in Fig. 19.) 


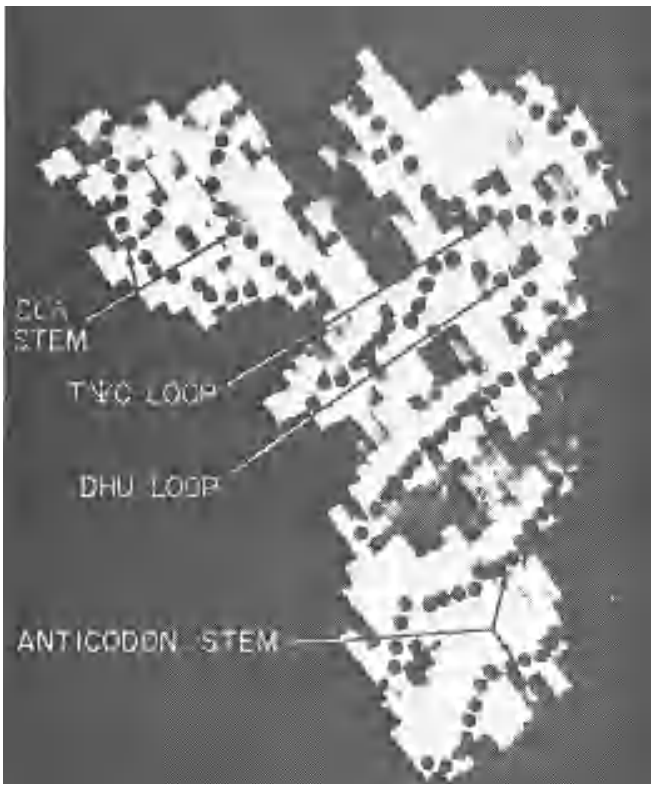

Fig. 19. Three-dimensional tRNA structure according to Rich. ${ }^{25}$

The picture of heat absorbance at tRNA absorbance somewhat varies with a change in salt conditions of the solution (Fig. 21), but is complicated in all the cases and the impression is created that the absorbance curve represents a set of peaks, i.e. we are dealing with several transitions. (A number of calorimetric works with quite contradictory results have been published recently on tRNA absorbance. ${ }^{28-30}$ )

If we assume that the transitions in the tRNA are independent and that each of them is a transition between two states, the curve of thermal capacity temperature dependence can be unambiguously separated into components, having in mind that the areas of separate peaks determining the effective and the Van't Hoff enthalpy must strictly correspond to the area which determines the calorimetric enthalpy. The result of such an analysis is given in the same Fig. 21. As is seen, in all the cases there is a standard set of components, but in different salt conditions they combine differently. In the presence of the $\mathrm{Mg}^{2+}$ ion some of them unite, that is, the cooperative regions merge.

As the tRNA structure is known, it is not difficult to identify the cooperative regions, since the area of the peaks should correspond to the number of bonds in the region and the temperature of the transition must depend directly on the G-C content. (For details $\operatorname{see}^{27}$.) It is natural to ascribe the largest heat absorption peak (with a value of $100 \mathrm{kcal} \mathrm{mol}^{-1}$ ) to the unfolding of the largest compact part of the molecule. This part is its middle part which includes an 'extra-loop' and a 'D-stem' united by a rather complex network of 10 bonds into a single system

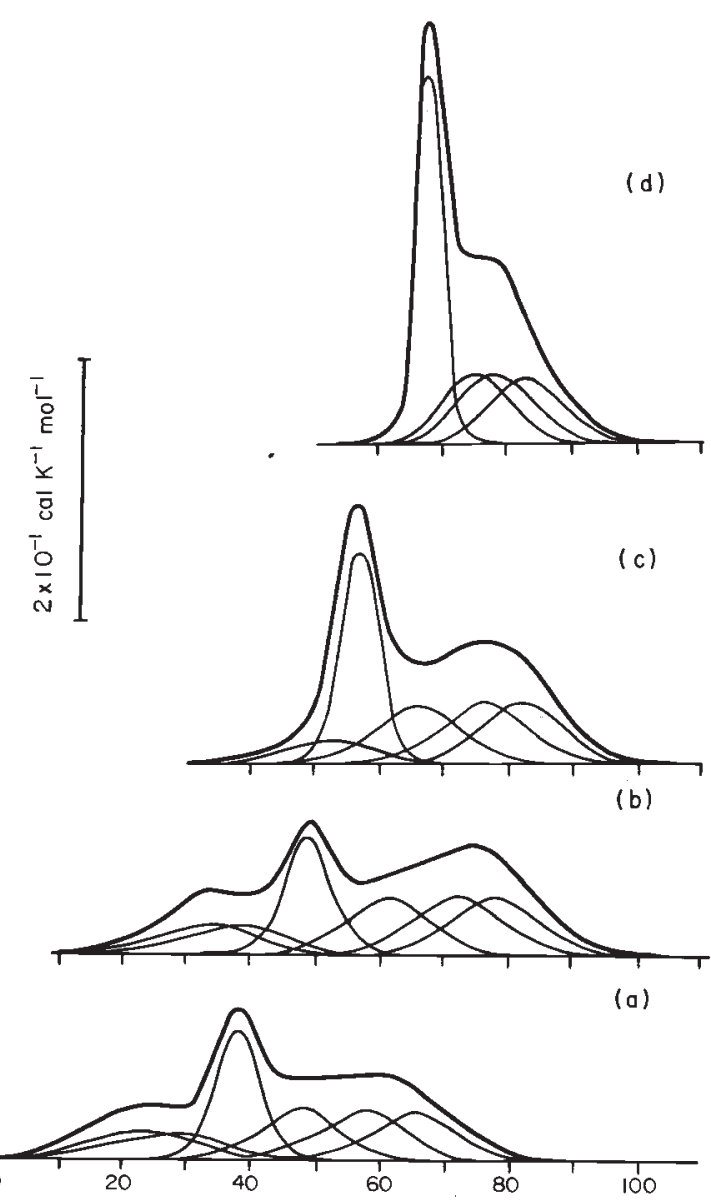

Fig. 21. Temperature dependence of heat absorbance at heating tRNA ${ }^{\text {val }}$ under different environment conditions: (a) salt-free, (b) $150 \mathrm{mM} \mathrm{NaCl}$, (c) $150 \mathrm{mM} \mathrm{NaCl}$ and $1 \mathrm{mM} \mathrm{MgCl}$ (d) $1 \mathrm{mM} \mathrm{MgCl}$.

(see Fig. 22). In the close neighbourhood of this region there are two small regions, the ' $\mathrm{T} \psi \mathrm{C}$-loop' and the 'D-loop', poorly distinguished on X-ray patterns. These are thermolabile structures which unfold even at room temperatures, and in the presence of $\mathrm{Mg}^{2+}$ they merge with the central part into one cooperative system. As concerns the three almost equal high-temperature peaks, their most probable ascription should be to the three almost equal double-helical structures existing in tRNA, the more so as helical structures must be the most stable ones. These helical structures are: the 'aminoacyl-stem' (7 pairs), the 'T $\psi$ C-stem' (6 pairs) and the 'anti-codon arm' (5 pairs and about 4 stackings).

The question arises: what is the cause for such a different breakdown behavior of the two compact structures, the tRNA and globular proteins?

The probable reason is that the nucleic acids are more inclined to form locked-in systems than polypeptides. The

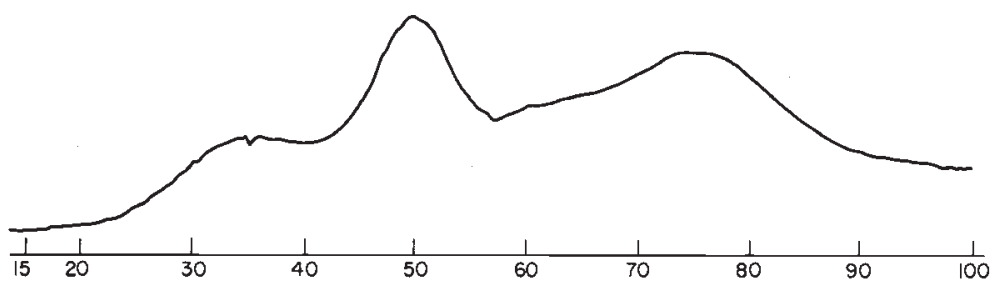

Fig. 20. A microcalorimetric recording of heat absorbance at heating the $\mathrm{RNA}^{\mathrm{Val}}$ solution (concentration $0.07 \%$, tRNA content $0.91 \mathrm{mg}$ ), $5 \mathrm{mM}$ phosphate buffer, $\mathrm{pH} 7.0$ ). 


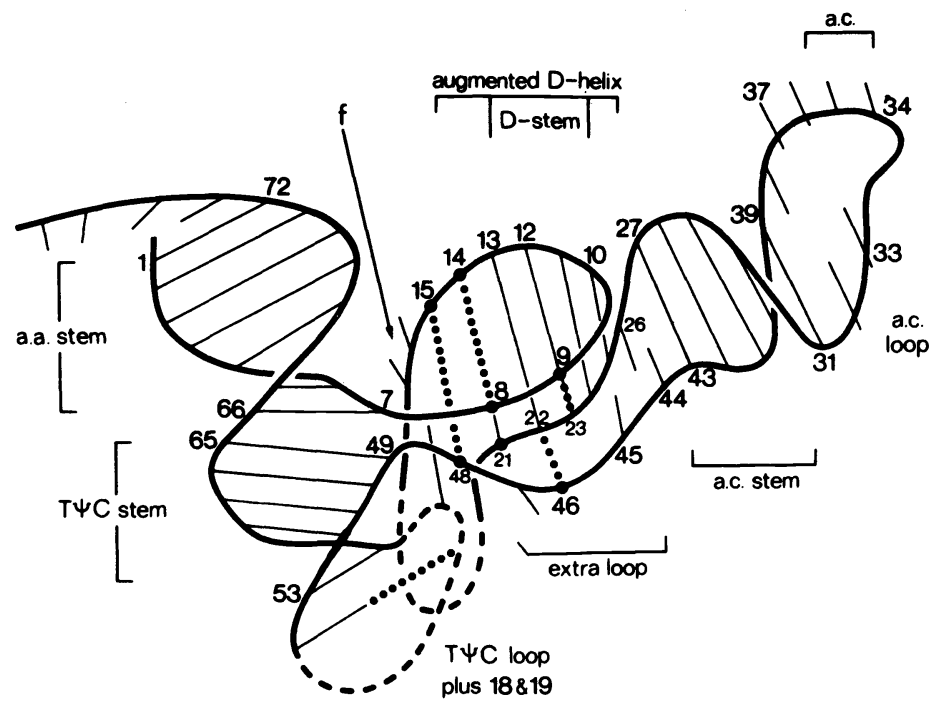

Fig. 22. Schematic representation of the tRNA structure according to Klug. ${ }^{26}$

elements constituting a nucleic acid (the bases) form bonds only in the direction perpendicular to the chain, and therefore in the presence of complementary regions they form locked-in structures-double helices. The elements of the polypeptide chain of proteins (the amino acid residues) form bonds in all directions and do not form locked-in systems though they have some tendency to do so. A refined analysis of protein structure reveals some regions with a stronger inner interaction. These regions are usually denoted as 'domains'. ${ }^{31,32}$

However, in contrast to the domains of nucleic acids, the protein domains are unstable. Their stability is provided only by interaction with other domains. Due to an essentially smaller interaction energy of the amino acids as compared to the interaction energy of nucleotides, the polypeptide chain can form a stable structure at a significantly larger size than the polynucleotide. This critical size for proteins apparently is in the region of 10,000 daltons, i.e. about 100 residues. Therefore it is not surprising that no independent substructures are observed in small globular proteins. But in large proteins they are displayed. An example of such a protein is Gimmunoglobulin. Its molecular weight is about 150,000 daltons. The picture of the heat absorbance on heating a solution of immunoglobulin is given in Fig. 23. From the rather complicated curve it is clear that melting proceeds in two separate stages. (This was shown recently by Zavialov and Khechinashvili in our laboratory.) The overall enthalpy of the process is $1200 \mathrm{kcal} / \mathrm{mol}$ of which about $300 \mathrm{kcal} / \mathrm{mol}$ pertain to the first and $900 \mathrm{kcal} / \mathrm{mol}$ to the second stages. However the effective enthalpy of the second process is only $150 \mathrm{kcal} / \mathrm{mol}$. Hence it follows that we are dealing with transitions in six cooperative regions. But it is known from structural data ${ }^{34}$ that immunoglobulin has 12 sharply distinct and very similar domains (see Fig. 24). It is clear from this that the cooperative system is formed by pairs of domains. As for the first transition, it is connected with some interdomain rearrangements, probably their separation.

It is worthwhile to consider collagen, a fibrous protein, as a second example of a protein system containing several cooperative regions. Its molecular weight is 360,000 daltons. The three polypeptide chains here are interlocked forming a triple helix $3000 \AA$ long (see Fig. 25). The collagen melting curve is given in Fig. $26{ }^{34}$ As can be seen, the transition is very sharp, from which it follows

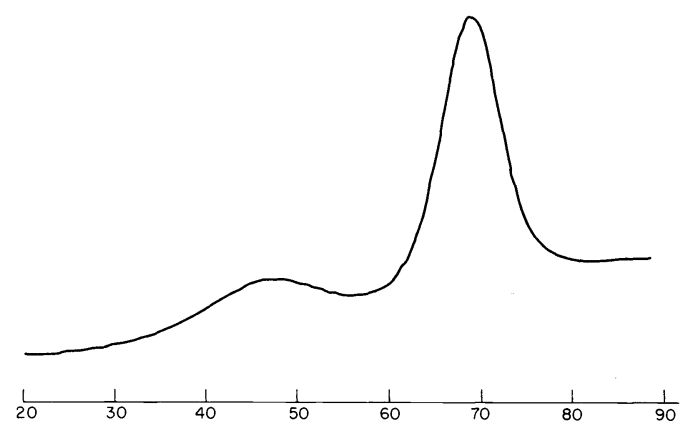

Fig. 23. Heat absorbance in the heated solution of Gimmunoglobulin at $\mathrm{pH}$ 3.3.
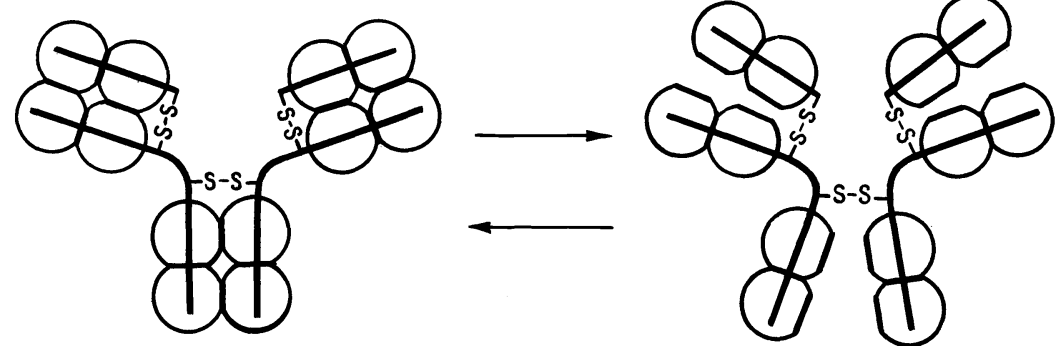

Fig. 24. Schematic representation of immunoglobulin domain structure and domain separation at the first transition. 


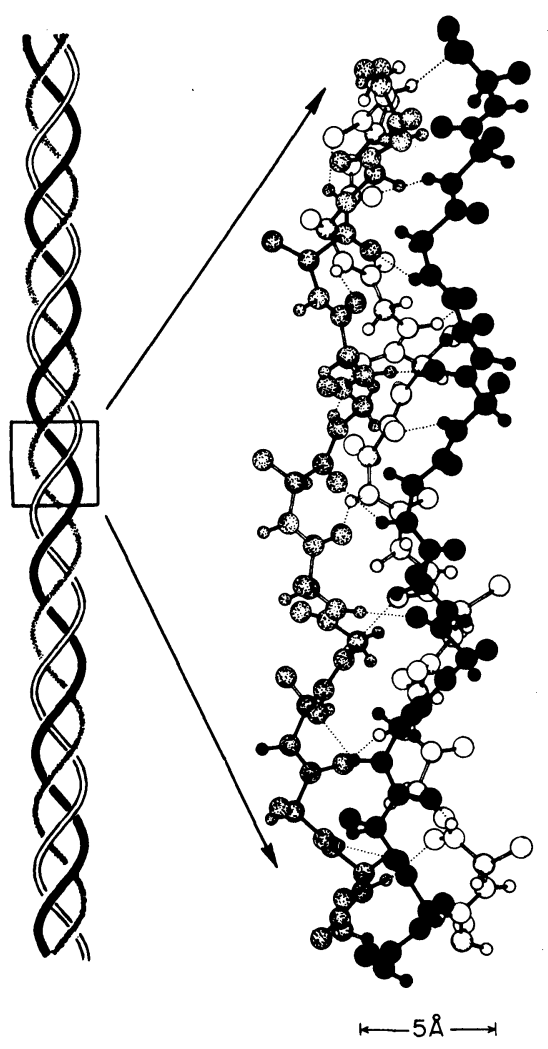

Fig. 25. Helical structure of collagen.

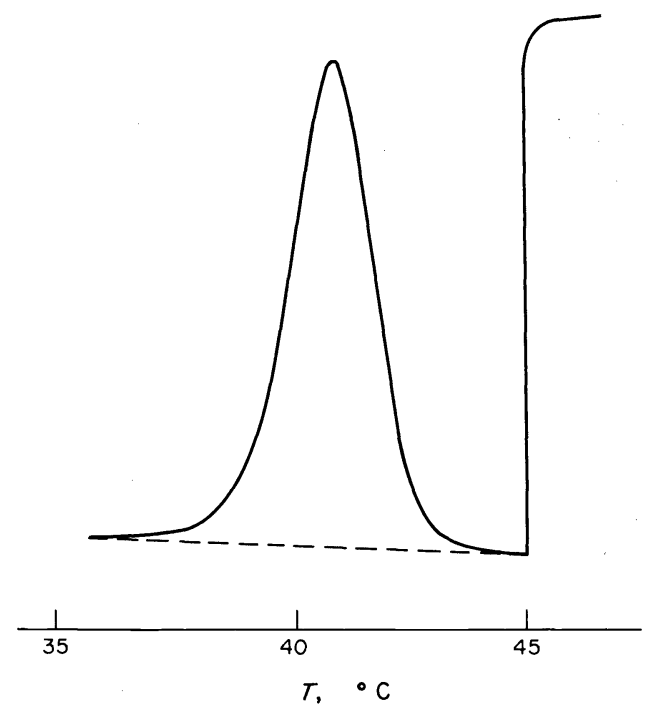

Fig. 26. Heat absorbance in the heated solution of collagen. Concentration $0.037 \%$, protein content $0.181 \mathrm{mg}$.

that the Van't Hoff enthalpy of the transition should be great. For rat-skin collagen it reaches $200 \mathrm{kcal} / \mathrm{mol}$. The calorimetric enthalpy is 30 times greater, $-5.7 \cdot 10^{6} \mathrm{cal} / \mathrm{mol}$. Hence it follows that the collagen molecule contains up to 30 cooperative regions. The molecular weight of each region is about 12,000 daltons.

It seems that the subdivision of domains is some general principle in the three-dimensional organization of biological macromolecules. However, it is by far unclear what this principle means and why the living nature uses it. It may be that it has some relation to the technology of assembly of the three-dimensional structure ${ }^{31}$ or perhaps, to the operation providing relative mobility of the parts of a protein molecule. It is not excluded, however, that the domain structure is required to ensure certain levels of cooperativity and stability. ${ }^{35}$

What level of stability is necessary in biological macromolecules?

One of the answers is apparent. For the protein to function and carry out its extremely specific and delicate work, it must be clearly defined in a wide range of external conditions. Its structure must not change qualitatively at slight variations of external conditions. Only in this case will the system be a reliable one.

However, in reality this question appears to be much more complex. The complication is that in creating protein Nature for some reason does not ensure its stability: The stability of protein determined as the difference of the Gibbs functions of the native and denatured states is not great (as was mentioned above, about $10 \mathrm{kcal} / \mathrm{mol}$ ). It appears that this stability correlates with the physiological temperature of the donor-animal, i.e. with the temperature at which protein operates. The lower the physiological temperature, the lower is the stability of a homologous protein.

This is most clearly seen in the example of collagen. Table 1 lists physiological temperatures and differences of the Gibbs functions at $25^{\circ} \mathrm{C}$ for collagens from different animals having various physiological temperatures. These collagens practically do not vary in structure, notwithstanding a somewhat different chemical content. The difference in the stability of these structures is great: cod collagen, as seen, is quite unstable at $25^{\circ} \mathrm{C} .^{34}$

Has the variation of stability any biological meaning?

An assumption was made (apparently the most consistive by Alexandrov ${ }^{36,37}$ ) that a certain level of mobility as well as stability of the protein structure is required for the functioning of protein. Could this be one of the criteria for nature in creating a protein molecule?

How must the mobility of the macomolecule structure be understood? Could it be the number of microdisruptions or the fluctuating defects of the structure?

If this is the case, the mobility can be quantitatively determined by the rate of incorporation of hydrogen isotopes into the structure of the macromolecule. Such studies are now in progress in many laboratories. ${ }^{38,39} \mathrm{We}$ have recently carried out a thermodynamic analysis of collagen mobility studying its hydrogen exchange rate. The results of this analysis are given in Fig. 27 as the logarithm dependence of the equilibrium constant for the unfolded form of collagen against inverse temperature.

Table 1. Thermodynamic characteristics of different collagens

\begin{tabular}{lccc}
\hline & $\begin{array}{c}\text { Physio- } \\
\text { logical } \\
\text { temperature } \\
\left({ }^{\circ} \mathrm{C}\right)\end{array}$ & $\begin{array}{c}\text { Denatura- } \\
\text { tion } \\
\text { temperature } \\
\left({ }^{\circ} \mathrm{C}\right)\end{array}$ & $\begin{array}{c}\text { Gibbs energy } \\
\text { of cooperative } \\
\text { region } \\
\text { stabilization } \\
\text { at } 25^{\circ} \mathrm{C} \\
(\mathrm{kcal} / \mathrm{mol})\end{array}$ \\
\hline $\begin{array}{c}\text { Object } \\
\begin{array}{c}\text { collagen } \\
\text { Pike-skin } \\
\text { collagen }\end{array}\end{array}$ & 37 & 41 & +10.0 \\
$\begin{array}{c}\text { Cod-skin } \\
\text { collagen }\end{array}$ & 10 & 31 & +3.4 \\
\hline
\end{tabular}




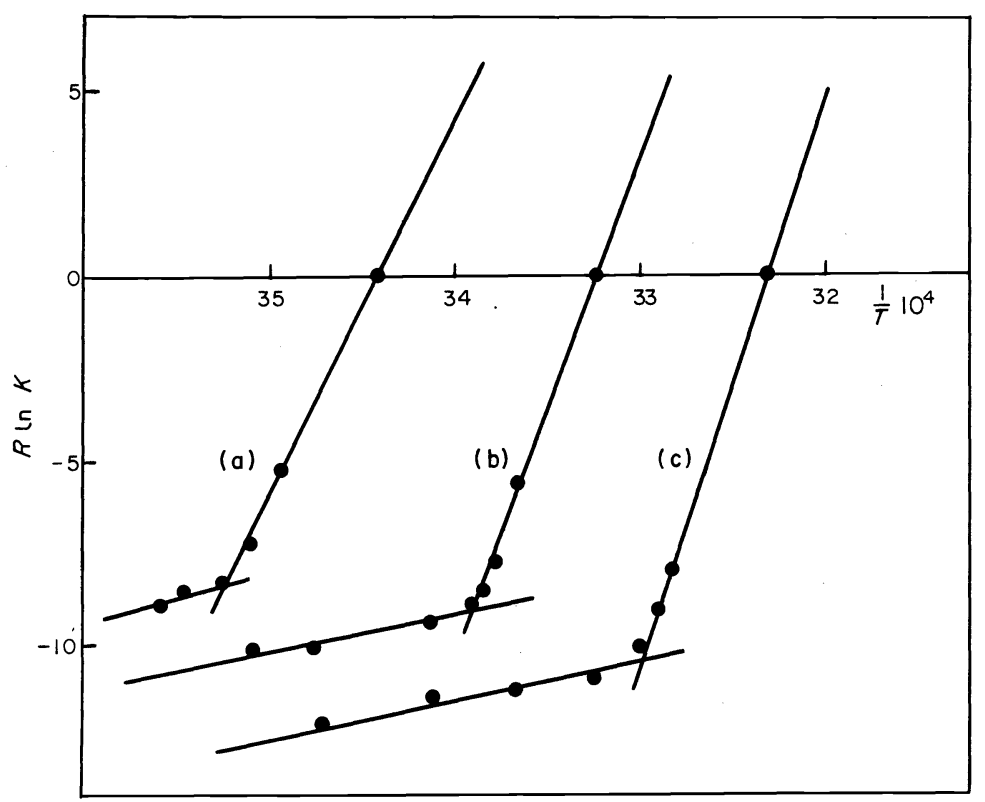

Fig. 27. Dependence of the equilibrium constants of collagen unfold against inverse temperature.

Since the slope of the curve in the chosen coordinates is nothing else than the enthalpy of structure unfolding, we see that at temperatures before denaturation the enthalpy of unfolding in all collagens is the same and small-only $1.5 \mathrm{kcal} / \mathrm{mol}$. In the denaturation region it increases by two orders. Here, undoubtedly, a new cooperative mechanism of unfolding is involved. As for the equilibrium constants, at $25^{\circ} \mathrm{C}$ and physiological temperatures they have the values given in Table 2. It is seen from the Table that for some reason the macromolecule requires the same low concentration of micro-unfolding or a certain level of micro-stability, if we speak of this in terms of the Gibbs energy of unfolding of the local region of the structure.

It is easy to see that the mechanism of microstability and macrostability, i.e. the stability of the local and cooperative regions, is qualitatively different. This follows not only from a sharp difference in the enthalpies of the local and cooperative transitions but rather from the difference in entropies: they are even of opposite signs. Nevertheless, both properties correlate with each other, both are determined by the protein structure and, moreover, by its functional state. Thus, the fixing of a ligand on the protein leads to a significant change in its macroscopic and microscopic stability. This was demonstrated in the example of fixing a specific inhibitor to

Table 2. Equilibrium constants for local unfoldings of different collagens at $25^{\circ} \mathrm{C}$ and physiological temperatures

\begin{tabular}{|c|c|c|c|}
\hline Object & $K_{25^{\circ} \mathrm{C}}$ & $\begin{array}{c}\text { Physiological } \\
\text { temperature } \\
\left({ }^{\circ} \mathrm{C}\right)\end{array}$ & $K_{\text {physiol. }}$ \\
\hline $\begin{array}{l}\text { Rat-skin } \\
\text { collagen }\end{array}$ & $3.6 \cdot 10^{-3}$ & 37 & $5.1 \cdot 10^{-3}$ \\
\hline $\begin{array}{l}\text { Pike-skin } \\
\text { collagen }\end{array}$ & $9.5 \cdot 10^{-3}$ & 10 & $5.2 \cdot 10^{-3}$ \\
\hline $\begin{array}{l}\text { Cod-skin } \\
\text { collagen }\end{array}$ & $86.0 \cdot 10^{-3}$ & 4 & $5.0 \cdot 10^{-3}$ \\
\hline
\end{tabular}

RNase $^{40}$ and lysozyme. ${ }^{41}$ This correlation between microscopic and macroscopic stability can be seen to a greater extent on parvalbumin, a calcium-binding protein. As was shown by Filimonov and Tiktopulo in our laboratory, when calcium is bound, the denaturation temperature changes by over $50^{\circ}$, from 40 to $90^{\circ}$. This was accompanied by a ten-fold change in the unfolding constant $K$ (from $3 \cdot 10^{-5}$ to $3 \cdot 10^{-6}$ ).

As yet we know very little of the mechanism of the described phenomena. Their clarification is a most immediate task of modern protein physics. Nonetheless, the achieved stage is essential, as it has led us not only to formulation of problems for the future, but also to the realization that biopolymers have specific thermodynamic properties and they must not be by-passed. Without their investigation we cannot get a further insight into the biological phenomena based on them. I do not know to what extent I managed to show this in my talk, but my chief intention was just this and not a complete review. That is why I have not discussed studies on the molecular level in biology using thermodynamic methods and have passed over many important separate problems, leaving them for the future.

\section{REFERENCES}

${ }^{1}$ P. L. Privalov, Biofizika 15, 206 (1970).

${ }^{2}$ I. Wadsö, Quart. Rev. Biophys. 3, 383 (1970).

${ }^{3}$ I. Wadsö, in: MTP International Review of Science, Physical Chemistry. Thermochemistry and thermodynamics. (editor N. A. Skiner) Vol. 10, Butterworth, London (1972).

${ }^{4} \mathrm{~J}$. M. Sturtevant, in: Methods in Enzymology. (editors C. H. W. Hirs and S. N. Timasheff) Vol. 26, p. 227. Academic Press, New York (1972).

${ }^{5}$ P. L. Privalov, FEBS Letters 40, S140 (1974).

${ }^{6} \mathrm{E}$. Schrödinger, What is Life-the Physical Aspect of the Living Cell. Cambridge Univ. Press, New York (1945).

${ }^{7}$ C. B. Anfinsen, Science 181, 223 (1973).

${ }^{8}$ C. Tanford, Adv. Prot. Chem. 23, 121 (1968).

${ }^{9}$ N. N. Khechinashvili, P. L. Privalov and E. I. Tiktopulo, FEBS Letters 30, 57 (1973). 
${ }^{10}$ P. L. Privalov and N. N. Khechinashvili, J. Mol. Biol. 86, 665 (1974).

${ }^{11}$ W. Pfeil and P. L. Privalov, Biophys. Chem. I. To be published.

${ }^{12} \mathrm{~J}$. Hermans, Jr. and G. Rialdi, Biochemistry 4, 1277 (1965).

${ }^{13}$ J. Hermans, Jr. and H. A. Scheraga, J. Am. chem. Soc. 83, 3283 (1961).

${ }^{14}$ W. Pfeil and P. L. Privalov, Biophys. Chem. II. To be published.

${ }^{15}$ S. Lapanje and I. Wadsö, Eur. J. Biochem. 22, 345 (1971).

${ }^{16} \mathrm{C}$. Tanford and R. C. Aune, Biochemistry 9, 206 (1970).

${ }^{17}$ W. Pfeil and P. L. Privalov, Biophys. Chem. III. To be published.

${ }^{18}$ P. L. Privalov, Biofizika 8, 308 (1963).

${ }^{19}$ R. Lumry, R. Biltonen and J. F. Brandts, Biopolymers 4, 917 (1966).

${ }^{20}$ W. M. Jackson and J. F. Brandts, Biochemistry 9, 2294 (1970)

${ }^{21}$ E. I. Tiktopulo and P. L. Privalov, Biophys. Chem. 1, 349 (1974).

${ }^{22} \mathrm{~J}$. Garel and R. L. Baldwin, Proc. Nat. Acad. Sci. USA 70, 3347 (1973).

${ }^{23} \mathrm{~J}$. F. Brandts, H. R. Halvorson and H. Brennan, Biochemistry 14, 4953 (1975).

${ }^{24}$ C. Levinthal, J. Chem. Phys. 65, 4 (1968).

${ }^{25}$ S. H. Kim, F. L. Suddath, G. J. Quigley, A. McPherson, J. L. Sussman, A. H. S. Wang, N. C. Seeman and A. Rich, Science 185, 435 (1974).

${ }^{26}$ J. D. Robertus, J. E. Ladner, J. T. Finch, D. Rhodes, R. D. Brown, B. F. C. Clark and A. Klug, Nature 250, 546 (1974).
${ }^{27}$ P. L. Privalov, V. V. Filimonov, T. V. Venkstern and A. A. Bayev, J. Mol. Biol. 97, 279 (1975).

${ }^{28}$ N. G. Bakradze, D. R. Monaselidze, A. D. Bibikova and L. L. Kisselev in: Conformational Changes of Biopolymers in Solutions. (editor E. L. Andronikashvili) p. 82. Nauka Publishing House, Moscow (1973).

${ }^{29}$ D. Bode, H. Schernau and Th. Ackermann, Biophys. Chem. 1, 214 (1974).

${ }^{30} \mathrm{~J}$. F. Brandts, W. M. Jackson and Th. Yao-Chung, Biochemistry 13, 3595 (1974).

${ }^{31}$ D. B. Wetlaufer. Proc. Nat. Acad. Sci. USA 70, 697 (1973).

${ }^{32}$ M. G. Rossmann and A. Liljas, J. Mol. Biol. 85, 177 (1974).

${ }^{33}$ G. M. Edelman, Science 180, 830 (1973).

${ }^{34}$ P. L. Privalov and E. I. Tiktopulo, Biopolymers 9, 127 (1970).

${ }^{35}$ O. B. Ptitsyn, Dokl. Akad. Nauk SSSR 223, 1253 (1975).

${ }^{36} \mathrm{~V}$. Ya. Alexandrov, Curr. Mod. Biol. 3, 9 (1969).

${ }^{37} \mathrm{~V}$. Ya. Alexandrov, Cells, Macromolecules and Temperature. Nauka Publishing House, Leningrad (1975).

${ }^{38}$ L. Willumsen, Compt. Rend. Lab. Carlsberg 38, 223 (1971).

${ }^{39}$ M. Nakanishi, M. Tsuboi and A. Ikegami, J. Mol. Biol. 75, 673 (1973).

${ }^{40}$ L. I. Pershina and A. Hvidt, Dokl. Akad. Nauk SSSR 220, 982 (1975).

${ }^{41}$ R. K. Wickett, G. J. Ide and A. Rosenberg, Biochemistry 13, 3273 (1974). 